\title{
Gestão de Custos Interorganizacionais: Fatores inibidores em Empresas do Setor Moveleiro do Distrito Federal
}

\author{
Rafael Araújo Sousa Farias \\ Doutorado em andamento em Administração pela Universidade de Brasília - UnB \\ Contador e Professor \\ Campus Darcy Ribeiro, Prédio da FACE. Asa Norte. Brasília/DF. CEP: 70.910-900 \\ E-mail: farias-rafael@hotmail.com \\ Valdirene Gasparetto \\ Doutorado em Engenharia de Produção pela Universidade Federal de Santa Catarina - \\ UFSC \\ Professora da Universidade Federal de Santa Catarina - UFSC \\ R. Eng. Agronômico Andrei Cristian Ferreira, s/n. Trindade. Florianópolis/SC. CEP: \\ 88.040-900 \\ E-mail: valdirenegasparetto@gmail.com
}

\section{RESUMO}

Este artigo analisa os fatores que inibem a prática da Gestão de Custos Interorganizacionais (GCl) em empresas do setor moveleiro do Distrito Federal. Participaram do estudo três empresas: uma fábrica de móveis, uma madeireira e uma loja de móveis. Conduziram-se entrevistas em profundidade, e os dados foram analisados mediante as técnicas Análise de Conteúdo e análise da tendência; e Intensidade de concordância quanto aos constructos, de modo a analisar os relacionamentos entre as empresas quanto aos fatores inibidores identificados na literatura. Os fatores inibidores: falta de gerenciamento voltado ao longo prazo, dependência de aprendizagem mútua, dificuldades relacionadas à integração de informações entre as empresas, nível insuficiente de dados compartilhados, ausência de conhecimento especializado e programas de educação voltados aos funcionários, desequilíbrio entre ganhos de curto e longo prazo, sistemas de $\mathrm{GCl}$ muito complexos e design do modelo da $\mathrm{GCl}$ mal elaborado foram apontados como presentes nos relacionamentos analisados. Conclui-se que a compreensão dos relacionamentos, a percepção de que as empresas estão interligadas, e o fato de conhecerem os processos e atividades das demais favorecem a $\mathrm{GCl}$. $\mathrm{O}$ bom relacionamento facilita a comunicação, a resolução de problemas e as negociações entre as empresas. Questões relacionadas à economia e à legislação interferem nos fatores inibidores da $\mathrm{GCl}$. Há fatores condicionantes da $\mathrm{GCl}$ que, para serem atingidos, precisam superar mais de um fator inibidor. Conclui-se, ainda, que há dificuldade de as empresas consideradas "não importantes" constituírem relacionamentos em longo prazo. Por fim, a falta de profissionais especializados em abordagens interorganizacionais não impossibilita sua aplicação. 
Gestão de Custos Interorganizacionais: Fatores inibidores em Empresas do Setor Moveleiro do

Distrito Federal

Rafael Araújo Sousa Farias, Valdirene Gasparetto

Palavras-chave: Gestão de Custos Interorganizacionais. Fatores Inibidores. Setor Moveleiro. Gestão Estratégica de Custos.

Interorganizational Cost Management: inhibiting Factors in the Furniture Industry of the Federal District

\section{ABSTRACT}

This article analyzes the factors that inhibit the practice of Interorganizational Cost Management (IOCM) in the furniture industry of the Federal District. Three companies participated in the study: a furniture factory, a lumber industry and a furniture store. We conducted in-depth interviews and the data were analyzed using the techniques of Content Analysis and analysis of the trend and intensity of agreement on the constructs, in order to analyze the relationships between the companies regarding the inhibitory factors identified in the literature. The following inhibiting factors: lack of long-term management goals, dependence of mutual learning, difficulties in integrating information between companies, inadequate level of data sharing, lack of expertise and education programs geared towards employees, imbalance between short-term and long-term gains, highly complex IOCM systems and poorly prepared IOCM model design were found in the analyzed relationships. It is concluded that the understanding of the relationships, the perception that companies are linked and the fact that they know the processes and activities of the other companies favor the IOCM. A good relationship facilitates communication, problem solving and negotiations between the companies. Issues related to the economy and legislation interfere with the inhibiting factors of the IOCM. There are conditioning factors of the IOCM that, in order to be achieved, need to overcome more than one inhibiting factor. It is observed that businesses considered unimportant have difficulties to establish long-term relationships. Lastly, lack of professionals specialized in interorganizational approaches does not prevent their implementation.

Key Words: Interorganizational Cost Management. Inhibiting Factors. Furniture Industry. Strategic Cost Management.

\section{INTRODUÇÃO}

Estudos recentes (Atouba \& Shumate 2010; Balestrin, Verschoore, \& Reyes Jr., 2010; Carter, Rogers, \& Choi, 2015; Kunzler \& Bulgacov, 2011; Lai, Zhang, Lee, \& Zhao, 2012; Müller-Seitz, 2011; Lee \& Monge, 2011; Poletto, Duarte, \& Mata, 2011; 
Gestão de Custos Interorganizacionais: Fatores inibidores em Empresas do Setor Moveleiro do Distrito Federal

Rafael Araújo Sousa Farias, Valdirene Gasparetto

Turrini, Cristofoli, Frosini, \& Nasi, 2010; Yamanoi \& Cao, 2014; Yan \& Gray, 1994) demonstram a importância dos relacionamentos interorganizacionais como forma de as empresas conseguirem vantagem competitiva diante do mercado. $O$ interesse e a percepção, por parte das empresas, da necessidade de arquitetar relações estratégicas com os membros de suas cadeias vêm aumentando a partir dos anos 1980 (Lambert \& Cooper, 2000).

A Gestão de Custos Interorganizacionais $(\mathrm{GCl})$ pode ser uma oportunidade para as empresas agregarem valor aos seus produtos. As empresas podem obter vantagem competitiva por meio da Gestão de Custos Interorganizacionais, cujo objetivo é encontrar soluções que apresentem resultados melhores quando comparados aos resultados das empresas ao agirem individualmente (Kulmala, Paranko \& Uusi-Rauva, 2002). Entretanto, Cooper e Slagmulder (2003) explicam que somente por meio de esforços conjuntos será possível atingir o objetivo de reduzir o custo total de operação da cadeia de suprimentos. Cooper e Slagmulder (1999) ressaltam que as empresas podem obter benefícios e vantagens com os inter-relacionamentos caso seja satisfeita uma série de fatores. As idiossincrasias e estratégias das empresas podem causar incompatibilidade entre suas ações; por exemplo, há empresas que visam à liderança pelo custo total, pela diferenciação ou, ainda, pelo enfoque (Porter, 1989). Cada uma dessas estratégias demanda ações distintas nas relações interorganizacionais. Além disso, o setor no qual a empresa está inserida interfere na aplicabilidade de estratégias de gerenciamento (Porter, 1989).

Referindo-se ao setor moveleiro brasileiro, a concorrência faz com que as empresas busquem estratégias para posicionarem-se frente aos concorrentes nacionais e internacionais (Flesch, 2010). Alves et al. (2008) explicam que a indústria moveleira brasileira vem se transformando em direção a uma gestão mais profissional. O setor é responsável por mais de 650 mil postos de trabalho, o que demonstra sua relevância (Abimóvel, 2016). Nesse contexto, o inter-relacionamento entre as empresas do setor moveleiro é possível, e a $\mathrm{GCl}$ apresenta-se como uma oportunidade, mas sua aplicação 
pode ser uma tarefa difícil. Observa-se que, dadas as vantagens proporcionadas, seria natural que a maioria das empresas buscasse o inter-relacionamento; paradoxalmente, ocorre o oposto (Kulmala, Paranko, Uusi-Rauva, 2002).

Considerando os trabalhos nacionais acerca da $\mathrm{GCl}$ publicados em periódicos (Aguiar, Rezende, \& Rocha, 2008; Camacho, Rocha, Moraes, \& Marques, 2014; Camacho, Rocha, Moraes, \& Marques, 2015; Campos, Oliveira, Leal, \& Duarte, 2015; Faria, Soares, Rocha, \& Rossi, 2013; Farias \& Gasparetto, 2016; Farias, Gasparetto, Lunkes, \& Schnorrenberger, 2016; Fehr \& Duarte, 2018; Gonzaga, Aillón, Fehr, Borinelli, \& Rocha, 2015; Horn, Bonfatti, \& Raupp, 2018; Moura \& Lima, 2016; Nascimento, Pereira, \& Scarpin, 2012; Oliveira, Borges, Carvalho, \& Santos, 2016; Souza, Braga, \& Krombauer, 2014; Xavier Júnior \& Lima, 2018), observa-se que os fatores inibidores não foram foco das pesquisas, apesar de alguns estudos fazerem um rápido levantamento e debate empírico sobre o tema (Camacho, Rocha, Moraes, \& Marques, 2014; Camacho, Rocha, Moraes, \& Marques, 2015; Campos, Oliveira, Leal, \& Duarte, 2015; Farias, Gasparetto, Lunkes, \& Schnorrenberger, 2016; Moura \& Lima, 2016). Assim, considerando exclusivamente esse escopo de trabalhos levantados, o presente estudo se caracteriza como o primeiro acerca do tema a relacionar a Gestão de Custos Interorganizacionais e os fatores inibidores, tendo como ambiente empresas do setor moveleiro.

Essa situação é vista, para o presente trabalho, como uma oportunidade de pesquisa. Desse modo, questiona-se: quais são os fatores que inibem a prática da Gestão de Custos Interorganizacionais em empresas do setor moveleiro do Distrito Federal? Este estudo possui o objetivo geral de analisar quais os fatores que inibem a prática da Gestão de Custos Interorganizacionais em empresas do setor moveleiro do Distrito Federal.

Bastl, Grubic, Templar, Harrison e Fan (2010) e Subramanian e Ishak (1998) explicam que os gestores encontram dificuldades em lidar com a complexidade dos problemas que impendem que as organizações obtenham êxito em suas ações 
Gestão de Custos Interorganizacionais: Fatores inibidores em Empresas do Setor Moveleiro do Distrito Federal

Rafael Araújo Sousa Farias, Valdirene Gasparetto

cooperadas. Nesse sentido, esta pesquisa visa contribuir com o debate acerca das dificuldades e potenciais obstáculos encontrados na abordagem da Gestão de Custos Interorganizacionais.

\section{REFERENCIAL TEÓRICO}

Gestão de Custos Interorganizacionais é uma abordagem estruturada que coordena as atividades das empresas em uma cadeia de fornecimento, para que os custos totais sejam reduzidos (Cooper \& Slagmulder, 1999). Souza e Rocha (2009, p. 25) afirmam que "Gestão de Custos Interorganizacionais é um processo cooperativo de gerenciamento de custos que inclui outras organizações de uma cadeia de valor além da própria empresa". A GCl visa reduzir custos relacionados à distribuição/logística e à fabricação dos produtos, com foco na coordenação das empresas e nas políticas de gestão de custos além das fronteiras organizacionais (Cooper \& Slagmulder, 1999).

As empresas, ao se relacionarem com outras organizações, buscam vantagens competitivas, como a possibilidade de combinação de competências, compartilhamento de know-how, divisão do ônus ao realizar pesquisas tecnológicas, divisão dos riscos e custos de explorar novas oportunidades, compartilhamento de recursos e fortalecimento do poder de compra (Amato Neto, 2000). Essa integração e coordenação das ações entre as empresas origina oportunidades, mas também desafios, já que as fronteiras tradicionais foram "quebradas" e as práticas de gestão de custos estão cada vez mais as transpondo (Coad \& Scapens, 2006). A coordenação das ações entre as empresas se torna ainda mais importante quando determinada organização não apresenta condições de reger, isoladamente, todos os fatores necessários para concluir determinado produto ou para obter certo resultado (Dekker, 2004; Kajüter \& Kulmala, 2005).

Há fatores que interferem na aplicabilidade da GCl (Cooper \& Slagmulder, 1999; Kajüter \& Kulmala, 2005; Souza \& Rocha, 2009), sendo nomeados de fatores 
condicionantes. "Fatores condicionantes da $\mathrm{GCl}$ são variáveis que influenciam o sucesso de implantação e utilização desse artefato gerencial" (Souza \& Rocha, 2009, p. 27). Cooper e Slagmulder (1999) e Souza e Rocha (2009) sugerem que cinco fatores sejam considerados na análise da aplicabilidade da $\mathrm{GCl}$ : Componentes, Mecanismos, Níveis de Relacionamento, Produtos e Tipos de Cadeia.

Além dos fatores condicionantes, há de se destacar os fatores inibidores que podem dificultar ou, até mesmo, impossibilitar o alcance dos objetivos aspirados pelas empresas. Bastl et al. (2010) destacam os fatores que inibem a implementação de abordagens de gestão de custos de maneira interorganizacional. Segundo os autores, sua pesquisa foi a primeira a abordar sistematicamente os fatores inibidores na implementação das abordagens de gestão de custos no âmbito interorganizacional. O estudo revelou a complexidade de fatores inibidores envolvidos na implementação das abordagens, além de demonstrar a interdisciplinaridade do tema. Bastl et al. (2010) sugerem que os fatores inibidores que acometem as abordagens de gestão de custos entre as empresas devam ser analisados em três dimensões: Pessoas, Processos e Tecnologia.

Noutro estudo, Farias e Gasparetto (2016) identificaram 30 fatores inibidores à $\mathrm{GCl}$, concluindo que a abordagem é um fenômeno interdisciplinar e que os relacionamentos colaborativos são pautados em muitos fatores distintos, porém a maioria dos fatores relaciona-se às pessoas, seus comportamentos e capacidades. Farias e Gasparetto (2016) optaram por dividir os fatores inibidores em três grupos, que se referem aos estágios distintos de desenvolvimento que os relacionamentos interorganizacionais assumem: planejamento das atividades e das estratégias, início das atividades e maturação dos relacionamentos (Chen, 2010; Ring \& Van De Ven, 1994). A Figura 1 demonstra os 30 fatores inibidores da GCl (Farias \& Gasparetto, 2016) que foram utilizados para conduzir a presente pesquisa. 
Gestão de Custos Interorganizacionais: Fatores inibidores em Empresas do Setor Moveleiro do

Distrito Federal

Rafael Araújo Sousa Farias, Valdirene Gasparetto

\begin{tabular}{|c|c|c|}
\hline Grupo 1 / Estágio 1 & Grupo 2 / Estágio 2 & Grupo 3 / Estágio 3 \\
\hline $\begin{array}{l}\text { Falta de recursos para executar } \\
\text { o projeto }\end{array}$ & $\begin{array}{c}\text { Falta de confiança entre os } \\
\text { parceiros de } \mathrm{GCl}\end{array}$ & $\begin{array}{l}\text { Desequilíbrio entre ganhos de } \\
\text { curto e longo prazo }\end{array}$ \\
\hline $\begin{array}{l}\text { Diferenças entre os } \\
\text { planejamentos estratégicos das } \\
\text { empresas }\end{array}$ & Oportunismo & Partilha desigual dos benefícios \\
\hline $\begin{array}{l}\text { Diferentes expectativas de } \\
\text { comportamento entre as } \\
\text { empresas }\end{array}$ & $\begin{array}{c}\text { Falta de incentivo para inovar e } \\
\text { prosperar }\end{array}$ & $\begin{array}{c}\text { Design do modelo da GCI mal } \\
\text { elaborado }\end{array}$ \\
\hline $\begin{array}{l}\text { Falta de gerenciamento voltado } \\
\text { ao longo prazo }\end{array}$ & Resistência à mudança & $\begin{array}{l}\text { Sistemas de GCl muito } \\
\text { complexos }\end{array}$ \\
\hline $\begin{array}{l}\text { Dependência de aprendizagem } \\
\text { mútua }\end{array}$ & $\begin{array}{c}\text { Falta de apoio por parte dos } \\
\text { membros da empresa }\end{array}$ & Rigidez na GCl \\
\hline $\begin{array}{l}\text { A ausência do reconhecimento } \\
\text { de que sistemas de custeio são } \\
\text { necessários }\end{array}$ & $\begin{array}{l}\text { Dificuldades relacionadas à } \\
\text { integração de informações entre } \\
\text { as empresas }\end{array}$ & $\begin{array}{l}\text { Incapacidade de determinar os } \\
\text { preços de mercado }\end{array}$ \\
\hline $\begin{array}{l}\text { Desinteresse, por parte das } \\
\text { empresas parceiras, em } \\
\text { compartilhar informações }\end{array}$ & $\begin{array}{l}\text { Falta de credibilidade dos dados } \\
\text { de custos internos }\end{array}$ & Perda de foco no cliente \\
\hline $\begin{array}{l}\text { Falta de compreensão de custos } \\
\text { ao longo da cadeia }\end{array}$ & $\begin{array}{c}\text { Nível insuficiente de dados } \\
\text { compartilhados }\end{array}$ & Objetivos iniciais não cumpridos \\
\hline $\begin{array}{l}\text { Ausência de percepção de valor } \\
\text { gerado pela relação }\end{array}$ & $\begin{array}{l}\text { Pobre disponibilidade interna de } \\
\text { dados }\end{array}$ & Conflitos constantes \\
\hline $\begin{array}{l}\text { Dificuldade em definir benefícios } \\
\text { mútuos }\end{array}$ & $\begin{array}{l}\text { Ausência de conhecimento } \\
\text { especializado e programas de } \\
\text { educação voltados aos } \\
\text { funcionários }\end{array}$ & $\begin{array}{c}\text { Falta de revisões periódicas de } \\
\text { desempenho }\end{array}$ \\
\hline
\end{tabular}

Figura 1. Fatores Inibidores da Gestão de Custos Interorganizacionais

Fonte: Adaptado de Farias e Gasparetto (2016)

O Grupo 1 é formado pelos fatores inibidores relacionados ao primeiro estágio do relacionamento interorganizacional: planejamento das atividades e das estratégias. Refere-se ao momento em que as empresas identificam oportunidades e vantagens que podem obter ao agir colaborativamente com fornecedores ou clientes. Nesse estágio, as empresas analisam seus perfis e estratégias e mapeiam oportunidades e processos que podem ser colocados em prática conjuntamente (Grandori \& Soda, 1995; Miles \& Snow, 1992; Stephenson, 2003).

O Grupo 2 é formado pelos fatores inibidores relacionados ao segundo estágio do relacionamento interorganizacional: início das atividades. Refere-se aos processos realizados para a obtenção de melhores resultados. Nesse estágio, as empresas 
Gestão de Custos Interorganizacionais: Fatores inibidores em Empresas do Setor Moveleiro do Distrito Federal

Rafael Araújo Sousa Farias, Valdirene Gasparetto

aumentam o compartilhamento de informações, recursos e coordenam as atividades (Doz, 1996; Oliver, 1990). É o momento em que o planejamento realizado no estágio inicial é colocado em prática (Grandori \& Soda, 1995; Nassimbeni, 1998).

O Grupo 3 compreende os fatores inibidores relacionados ao terceiro estágio do relacionamento interorganizacional: maturação dos relacionamentos. É o momento em que as empresas obtêm os primeiros resultados e são capazes de avaliar se as relações trouxeram vantagens, se o planejamento e os objetivos iniciais foram alcançados e, assim, podem realizar os ajustes necessários para a manutenção dos relacionamentos, caso julguem necessários (Miles \& Snow, 1992; Stephenson, 2003).

\section{PROCEDIMENTOS METODOLÓGICOS}

Para alcançar o objetivo proposto, inicialmente foram contatados os escritórios do Serviço Brasileiro de Apoio às Micro e Pequenas Empresas do Distrito Federal (SEBRAE/DF) e do Sindicato das Indústrias da Madeira e do Mobiliário do Distrito Federal (SINDIMAM/DF). Os contatos ocorreram de maneira presencial, por telefone e e-mail. Desse modo, obtiveram-se informações preliminares acerca das empresas e do setor moveleiro do DF, complementadas com acesso aos websites das empresas.

Na sequência, cinco fábricas de móveis foram visitadas, tendo sido explicados às empresas os objetivos da pesquisa e exposta a proposta de entrevista em profundidade. Duas fábricas de móveis aceitaram participar da entrevista, entretanto, optou-se por realizar o estudo em apenas uma. A fábrica escolhida para participar demonstrou ser um caso mais complexo e com potencial de colaborar com o debate acerca da $\mathrm{GCl}$. Além da fábrica de móveis, outras duas empresas participaram do estudo: uma madeireira e uma loja de móveis - respectivamente fornecedor e distribuidor - considerados como os principais parceiros da fábrica.

A coleta de dados ocorreu por meio da realização de entrevistas em profundidade e respondidas pelo gerente de produção da fábrica, pelo gerente de 
compras da loja e pelo vice-presidente da madeireira. Durante cada entrevista em profundidade, foram utilizados dois instrumentos de coleta de dados: um roteiro de entrevista flexível e um questionário em escala Likert. O roteiro de entrevista flexível e o questionário foram elaborados por Farias (2016), baseado nos fatores inibidores da literatura. Os instrumentos de coleta de dados que foram submetidos à técnica de préteste têm como objetivo identificar o relacionamento entre as empresas e identificar os problemas e os fatores inibidores da $\mathrm{GCl}$ presentes nas relações.

O questionário foi estruturado de modo a ser respondido por escala Likert de 5 pontos, de 1 (discordo totalmente) a 5 (concordo totalmente), para as perguntas referentes aos constructos (fatores inibidores). Para a análise, as respostas de 1 a 5 receberam valores de -2 a +2 , observando o sentido das afirmações (Martins \& Theóphilo, 2009). O questionário aplicado possui 2 itens para cada fator inibidor; assim, a pontuação máxima que cada fator poderia receber (na opinião de cada respondente) seria 4 e a pontuação mínima seria -4 , sendo a mediana representada pelo valor 0 . Martins e Theóphilo (2009) explicam que essa análise é utilizada para saber qual é a tendência das repostas e sua intensidade quando comparado aos outros constructos.

Os dados foram analisados e descritos mediante a técnica de Análise de Conteúdo (Flick, 2004). Ademais, a análise da escala Likert, como sugerido por Martins e Theóphilo (2009), permitiu identificar a tendência das repostas e sua intensidade quanto a cada um dos construtos da escala (Farias, 2016). Ainda, foi possível realizar a comparação entre as respostas obtidas de cada uma das empresas para os constructos. Após esses procedimentos, as respostas determinaram quais fatores inibidores, e suas respectivas intensidades, estavam presentes nas relações entre as empresas.

As entrevistas foram gravadas com a autorização prévia dos entrevistados. Ocorreram durante os meses de dezembro de 2015 e janeiro de 2016 e aconteceram na sede das empresas. O material coletado foi transcrito, e trechos das respostas estão presentes neste estudo. Para diminuir o desinteresse e a barreira em participar do 
estudo, foi assegurado aos entrevistados o anonimato, a confidencialidade em relação à divulgação de informações que permitam sua identificação e uso exclusivo para a realização deste trabalho.

Dentre as limitações da presente pesquisa, estão: (a) impossibilidade de generalizar os achados a outras relações interorganizacionais; (b) respostas advindas de um único respondente por empresa; (c) análise de empresas de um único setor; e (d) apenas parte de uma cadeia de suprimentos analisada. Hair Jr., Barry, Money e Samouel (2005) apontam que há risco de o próprio processo de entrevista influenciar os entrevistados, além de as respostas obtidas não serem totalmente precisas, devido à recordação incompleta, à supressão de informações causada por preocupações sociais ou à falta de disposição para dar uma resposta precisa à pergunta.

\section{RESULTADOS E ANÁLISES}

\subsection{Empresas Participantes da Pesquisa}

Participaram da pesquisa três empresas da cadeia produtiva moveleira do Distrito Federal. A Figura 2 evidencia, para a cadeia genérica do setor moveleiro, os membros da cadeia analisados neste estudo. 
Gestão de Custos Interorganizacionais: Fatores inibidores em Empresas do Setor Moveleiro do

Distrito Federal

Rafael Araújo Sousa Farias, Valdirene Gasparetto

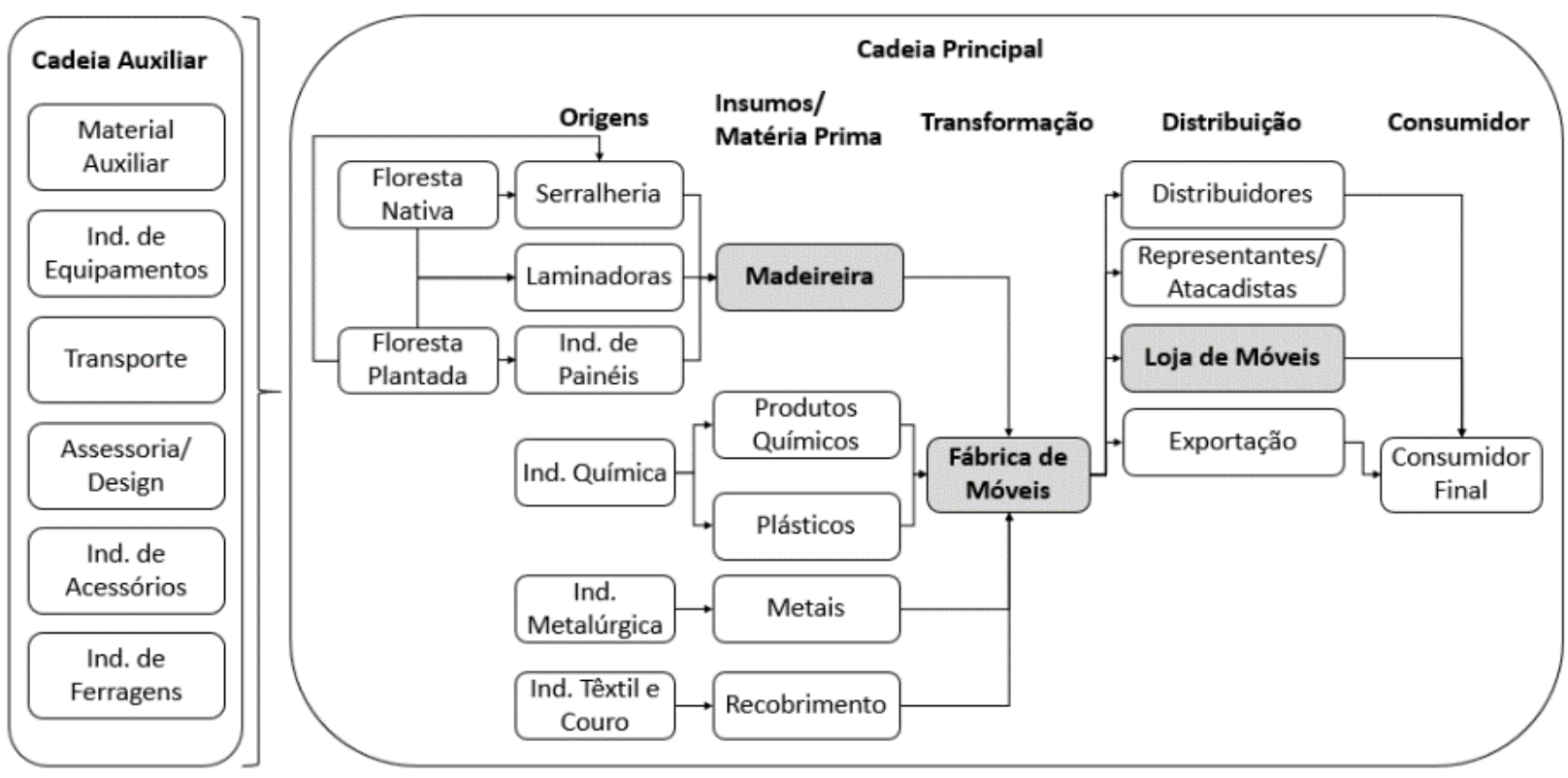

Figura 2. Relacionamentos da empresa focal analisados

Fonte: Adaptada de IPT (2002).

A madeireira foi fundada no ano 2000 e, atualmente, possui 65 funcionários. A empresa disponibiliza madeira para construção, vigamento e acabamento, além de disponibilizar madeiras tratadas para produção de móveis e projetos. Atua no Distrito Federal e nas cidades do entorno. Comercializa seus produtos, principalmente, na modalidade de atacado para as fábricas de móveis e se relaciona há mais de 11 anos com a empresa focal deste estudo. O membro representante da empresa que participou da pesquisa foi o vice-presidente, sócio e filho do fundador da empresa. $O$ entrevistado trabalha na empresa há 12 anos e possui formação acadêmica em administração de empresas.

A fábrica de móveis foi fundada no ano de 1985 e, atualmente, possui 120 funcionários. Possui como principais matérias-primas para sua produção o Medium Density Fiber (MDF), madeira maciça (madeiras nobres), laminado de madeira e, em menores quantidades, tecidos, espuma, ferro, alumínio e vidro. A empresa está situada no Distrito Federal e comercializa seus produtos, principalmente, com lojas de móveis 
Gestão de Custos Interorganizacionais: Fatores inibidores em Empresas do Setor Moveleiro do Distrito Federal

Rafael Araújo Sousa Farias, Valdirene Gasparetto

da região Centro-Oeste, Nordeste e Sudeste. A fábrica possui como principal fonte de faturamento a venda de seus produtos para lojas especializadas em móveis que, por sua vez, praticam a venda direta ao consumidor. O membro representante da empresa que participou da pesquisa foi o gerente de produção da fábrica, que trabalha há oito anos na empresa, atuando no cargo há seis anos. Possui como formação acadêmica o curso de administração de empresas.

A loja de móveis foi fundada em 1998. Emprega 55 funcionários e possui como negócio a venda de móveis. Está localizada no Distrito Federal e comercializa seus produtos nessa região. A empresa comercializa, principalmente, produtos de 4 grandes fornecedores de móveis e se relaciona há mais de 10 anos com a empresa focal deste estudo. Possui seu faturamento caracterizado pela venda direta de móveis ao consumidor, além de móveis planejados. O membro representante da empresa que participou da pesquisa foi o gerente de compras, que trabalha na empresa há 5 anos. $O$ gerente possui como formação o curso de design de interiores.

\subsection{Entrevistas com as Empresas}

O representante da fábrica optou por utilizar o termo "parceiros" para referir-se simultaneamente à madeireira e à loja que também foram entrevistadas neste estudo. Quanto às entrevistas realizadas com a madeireira e a loja de móveis, as perguntas foram realizadas referindo-se sempre à fábrica participante do estudo.

De maneira genérica, sem especificar situações, a fábrica indicou que sua empresa e os parceiros buscam, conjuntamente, aumentar a eficiência da interação entre si, melhorar a elaboração dos produtos e flexibilizar prazos de entrega para se ajustar aos interesses dos parceiros. Segundo a fábrica, os parceiros colaboram com a engenharia de seus produtos e buscam a redução de custos mediante o redesenho de produtos. Para exemplificar, o entrevistado explicou que, por vezes, a fábrica muda o projeto de seus produtos para acomodar um componente de baixo custo disponibilizado pela madeireira. 
Ainda nesse contexto - de ações conjuntas relacionadas à engenharia e design dos produtos - a fábrica refere-se à loja de móveis como uma importante parceira, ao passo que disponibiliza à sua empresa suporte para identificar oportunidades de melhoria no design de seus produtos. $O$ fato de possuir funcionários especializados (arquitetos, designers e vendedores) e por estar em contato com o consumidor final, possui facilidade em interpretar as tendências e necessidades do mercado.

As Figuras 3 a 10 demonstram as respostas obtidas durante as entrevistas, referentes aos fatores inibidores identificados como presentes nos relacionamentos. Desse modo, dos 30 fatores inibidores analisados (Figura 1), 8 foram identificados nos relacionamentos entre as empresas. As figuras evidenciam o valor referente à escala Likert e trechos das falas dos entrevistados.

A Figura 3 demonstra as respostas referentes ao fator inibidor falta de gerenciamento voltado ao longo prazo (deste ponto em diante, ao longo do texto, os fatores inibidores estão destacados em negrito).

\begin{tabular}{|l|l|l|}
\hline Resposta da Madeireira & \multicolumn{1}{|c|}{ Respostas da Fábrica } & \multicolumn{1}{|c|}{ Respostas da Loja } \\
\hline Likert: 0 & \multicolumn{1}{|c|}{ Likert: 3 } & \multicolumn{1}{c|}{ Likert: 2 } \\
\hline Entrevista: & Entrevista: & Entrevista: \\
Acho difícil um planejamento de & A falta de visão do futuro atrapalha o & É difícil falar em longo prazo. \\
longo prazo com qualquer & gerenciamento de tudo relacionado à & Nós vamos encarando os \\
empresa; a situação econômica & empresa, não apenas os & desafios aos poucos es \\
dos consumidores muda muito. & relacionamentos com fornecedores e & tentando nos moldar aos \\
A fábrica de móvel não pode & clientes. Nós pensamos um ano de & cenários. É perigoso firmar \\
sinalizar de maneira confiável a & cada vez. O mercado de móveis aqui & acordos em longo prazo com \\
quantidade e tipo de madeira & no Brasil sofre mudanças & fornecedores. A fábrica é \\
que comprarão da gente. Isso & constantemente. Muda o poder de & uma grande parceira, mas \\
acontece porque nem a própria & compra das pessoas, o desemprego & os pedidos são feitos aos \\
fábrica, muitas vezes, possui & aumenta, há mudanças na legislação & poucos. \\
essa informação. Essa & referente a impostos e a questões & \\
insegurança e imprevisibilidade & ambientais. Produtos chineses vêm & \\
do setor atrapalha nosso & ganhando espaço no Brasil. Tudo & \\
planejamento e e inibe & isso faz com que planejamento em & \\
investimentos. & longo prazo seja algo difícil. & \\
\hline
\end{tabular}

Figura 3. Respostas obtidas mediante as perguntas referentes ao fator inibidor falta de gerenciamento voltado ao longo prazo

Fonte: Dados da pesquisa. 
Autores apontam que a construção de relacionamentos interorganizacionais necessita de planejamento e ações voltadas para o longo prazo (Boddy, Macbeth, \& Wagner, 2000; Ellram, 1996; Kajüter \& Kulmala, 2005; Kumra, Agndal, \& Nilsson, 2012). A principal fundamentação para isso é que a construção de confiança e o aprimoramento das ações coordenadas necessitam de tempo (Cooper \& Slagmulder, 1999). Nas empresas analisadas, a falta de gerenciamento voltado ao longo prazo foi apontada não devido à negligência ao negócio ou atrito entre as estratégias das empresas, mas devido às dificuldades e incertezas do mercado. Para os entrevistados, o gerenciamento e planos voltados para o longo prazo (considerado nas entrevistas como um período de três anos) é algo difícil de ser executado. Além disso, eles não souberam descrever o cenário em que estariam três anos à frente.

A Figura 4 demonstra as respostas referentes ao fator inibidor ausência de conhecimento especializado e programas de educação voltados aos funcionários.

\begin{tabular}{|c|c|c|}
\hline Resposta da Madeireira & Respostas da Fábrica & Respostas da Loja \\
\hline Likert: 3 & Likert: 1 & Likert: 3 \\
\hline $\begin{array}{l}\text { Entrevista: } \\
\text { Nossos funcionários não } \\
\text { receberam conhecimento } \\
\text { especializado ou } \\
\text { treinamento para que } \\
\text { pudessem trabalhar de } \\
\text { maneira colaborativa com } \\
\text { os clientes. Considero que } \\
\text { poderíamos obter melhores } \\
\text { resultados caso tivéssemos } \\
\text { especialistas na área. }\end{array}$ & $\begin{array}{l}\text { Entrevista: } \\
\text { Nossos funcionários não receberam } \\
\text { cursos para trabalharem } \\
\text { colaborativamente com os parceiros, } \\
\text { mas acredito que o tempo e } \\
\text { experiência dos funcionários ameniza } \\
\text { esse problema. Acredito que, caso } \\
\text { meus funcionários conjuntamente } \\
\text { com os funcionários dos fornecedores } \\
\text { e distribuidores recebessem } \\
\text { treinamento ospecializado, } \\
\text { poderíamos obter melhores } \\
\text { resultados. }\end{array}$ & $\begin{array}{l}\text { Entrevista: } \\
\text { Não foi disponibilizado } \\
\text { treinamento para os } \\
\text { funcionários sobre ações } \\
\text { coordenadas com fornecedores. } \\
\text { Acredito que obteríamos } \\
\text { melhores resultados caso } \\
\text { contratássemos profissionais } \\
\text { especializados ou, até mesmo, } \\
\text { uma consultoria. }\end{array}$ \\
\hline
\end{tabular}

Figura 4. Respostas obtidas mediante as perguntas referentes ao fator inibidor ausência de conhecimento especializado e programas de educação voltados aos funcionários Fonte: Dados da pesquisa.

O conhecimento especializado acerca da Gestão de Custos Interorganizacionais e de conceitos relacionadas ao tema é visto como um importante fator para a 
Gestão de Custos Interorganizacionais: Fatores inibidores em Empresas do Setor Moveleiro do Distrito Federal

Rafael Araújo Sousa Farias, Valdirene Gasparetto

construção dos projetos com fornecedores e clientes (Cokins, 1998; Cooper \& Slagmulder, 1999; Dyer \& Hatch, 2006; Himme, 2012; Lalonde \& Pohlen, 1996; Ramos, 2004). Observa-se que as empresas analisadas possuem conhecimento de seus negócios e geram informações sobre seus custos e atividades. Entretanto, acreditam que poderiam obter melhores resultados e aproveitar oportunidades com projetos da $\mathrm{GCl}$ com fornecedores/clientes caso possuíssem profissionais mais qualificados, o que levou a presente pesquisa a considerar ausência de conhecimento especializado e programas de educação voltados aos funcionários como um fator inibidor. Referindo-se ao compartilhamento de informações entre sua empresa e as duas parceiras, a fábrica destaca que o compartilhamento de informações ocorre, principalmente, no momento de realizar previsões conjuntas, analisar metas de desempenho e previsões de venda.

A Figura 5 demonstra as respostas referentes ao fator inibidor design do modelo da GCI mal elaborado.

\begin{tabular}{|c|c|c|}
\hline Resposta da Madeireira & Respostas da Fábrica & Respostas da Loja \\
\hline Likert: 0 & Likert: 2 & Likert: 1 \\
\hline $\begin{array}{l}\text { Entrevista: } \\
\text { Caso tivéssemos profissionais } \\
\text { especializados para integrar } \\
\text { nossas empresas e coordenar } \\
\text { esforços, poderíamos obter } \\
\text { melhores resultados. }\end{array}$ & $\begin{array}{l}\text { Entrevista: } \\
\text { Caso contratássemos } \\
\text { consultores para nos auxiliar e } \\
\text { mostrar maneiras de interligar } \\
\text { nossas ações com as dos } \\
\text { fornecedores e dos clientes, } \\
\text { conseguiríamos melhores } \\
\text { resultados. }\end{array}$ & $\begin{array}{l}\text { Entrevista: } \\
\text { O relacionamento e a elaboração de } \\
\text { projetos poderiam ser melhor } \\
\text { conduzidos caso tivéssemos pessoal } \\
\text { preparado e treinado para isso. }\end{array}$ \\
\hline
\end{tabular}

Figura 5. Respostas obtidas mediante as perguntas referentes ao fator inibidor design do modelo da GCI mal elaborado

Fonte: Dados da pesquisa.

Waeytens e Bruggeman (1994) apontam que problemas no design dos modelos relacionados à gestão de custos pode impedir que as empresas consigam apurar seus custos corretamente e, então, tenham dificuldades em colaborar com os membros de sua cadeia. Um design do modelo da $\mathrm{GCl}$ mal elaborado, com atividades mal 
formuladas, que não fornece o real custo das atividades da empresa é visto como uma barreira para a GCl (Cokins, 1998, 2003; Kaplan \& Anderson, 2004). Os respondentes concordam que conseguiriam melhores resultados e que os projetos seriam melhor elaborados caso possuíssem profissionais especializados nessa área. Afirmam que sentem dificuldade em desenvolver projetos interorganizacionais e que o fator design do modelo da $\mathrm{GCl}$ mal elaborado poderia ser evitado com a presença de profissionais especializados.

A Figura 6 demonstra as respostas referentes ao fator inibidor nível insuficiente de dados compartilhados.

\begin{tabular}{|c|c|c|}
\hline Resposta da Madeireira & Respostas da Fábrica & Respostas da Loja \\
\hline Likert: -3 & Likert: 2 & Likert: 2 \\
\hline $\begin{array}{l}\text { Entrevista: } \\
\text { Precisamos conversar com a } \\
\text { fábrica para ajudá-la a decidir } \\
\text { qual é a melhor opção para } \\
\text { seus produtos. Nossas } \\
\text { empresas possuem troca de } \\
\text { informações e sistema que } \\
\text { mostra o nosso histórico de } \\
\text { entrega. Nunca aconteceu de a } \\
\text { fábrica me solicitar informações } \\
\text { que não quisesse compartilhar. }\end{array}$ & $\begin{array}{l}\text { Entrevista: } \\
\text { A integração de nossas informações } \\
\text { ocorre por meio de reuniões periódicas } \\
\text { com os fornecedores e clientes, além } \\
\text { de e-mail, Skype e telefone. Com o } \\
\text { tempo as boas relações com os } \\
\text { clientes e fornecedores facilitam o fluxo } \\
\text { e a velocidade da troca de } \\
\text { informações. O que facilita o dia-a-dia } \\
\text { da empresa é você saber } \\
\text { especificamente com qual funcionário } \\
\text { deve falar na empresa; isso faz } \\
\text { economizar tempo. }\end{array}$ & $\begin{array}{l}\text { Entrevista: } \\
\text { Não interferimos nos } \\
\text { processos produtivos das } \\
\text { fábricas. Conversamos } \\
\text { mais sobre o design dos } \\
\text { produtos, sobre prazos e } \\
\text { metas. }\end{array}$ \\
\hline
\end{tabular}

Figura 6. Respostas obtidas mediante as perguntas referentes ao fator inibidor nível insuficiente de dados compartilhados

Fonte: Dados da pesquisa.

Davenport, Harris e Cantrell (2004) explicam que sistemas que disponibilizam informações sobre as atividades das organizações, como o Enterprise Resource Planning (ERP) podem ajudar as empresas a superar o fator inibidor nível insuficiente de dados compartilhados; entretanto, pode ter sua funcionalidade limitada caso essas não saibam usufruir de suas vantagens. Observa-se que a madeireira reforça a ideia de que o compartilhamento de informações com a fábrica ocorre em um nível suficiente. Já 
a fábrica e a loja reiteram que, caso houvesse mais trocas de informações entre suas empresas, obteriam melhores resultados. A fábrica explica que dispensa mais atenção àquelas empresas que considera parceiras.

A Figura 7 demonstra as respostas referentes ao fator inibidor dificuldades relacionadas à integração de informações entre as empresas.

\begin{tabular}{|c|c|c|}
\hline Resposta da Madeireira & Respostas da Fábrica & Respostas da Loja \\
\hline $\begin{array}{l}\text { Likert: } 1 \\
\end{array}$ & Likert: 1 & Likert: 0 \\
\hline $\begin{array}{l}\text { Entrevista: } \\
\text { Qualquer pergunta que a } \\
\text { fábrica me pedir eu posso } \\
\text { disponibilizar a ela. basta o } \\
\text { gerente me ligar e perguntar; } \\
\text { não precisamos de um } \\
\text { programa que mostre o } \\
\text { quanto de cada madeira } \\
\text { tenho no estoque ou algo } \\
\text { assim. }\end{array}$ & $\begin{array}{l}\text { Entrevista: } \\
\text { Um sistema integrado com eles não } \\
\text { temos. Cada um possui programas que } \\
\text { mostram o histórico de venda e de } \\
\text { compras. Acredito que, caso } \\
\text { pudéssemos ter informações online dos } \\
\text { fornecedores e de seus estoques, } \\
\text { poderíamos trocar mais informações e } \\
\text { ser mais eficientes; evitaria tantos } \\
\text { telefonemas. }\end{array}$ & 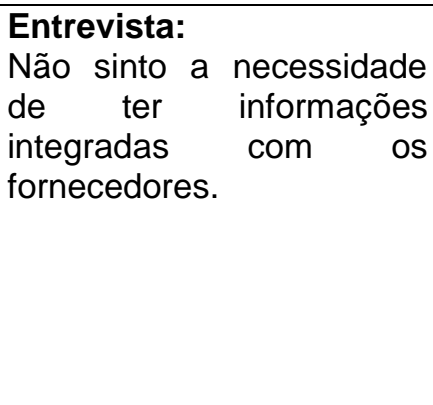 \\
\hline
\end{tabular}

Figura 7. Respostas obtidas mediante as perguntas referentes ao fator inibidor dificuldades relacionadas à integração de informações entre as empresas Fonte: Dados da pesquisa.

No processo de cooperação entre as empresas, novas características surgem, como o aumento da complexidade e a necessidade de trabalhar dentro e fora das fronteiras da organização. De tal modo, trabalhar colaborativamente requer a utilização de dados externos à empresa, o que exige a integração dessas informações (Ramos, 2004). Ressaltam-se as dificuldades relacionadas à integração de informações entre as empresas. Os três entrevistados confirmaram a inexistência de programas que integrem suas informações internas. A madeireira e a loja não sentem a necessidade de um sistema desses e acreditam que não é um fator que interfere em seu desempenho. Por sua vez, a fábrica afirma que um sistema facilitaria suas atividades e o relacionamento com os parceiros.

A Figura 8 demonstra as respostas referentes ao fator inibidor dependência de aprendizagem mútua. 


\begin{tabular}{|c|c|c|}
\hline Resposta da Madeireira & Respostas da Fábrica & Respostas da Loja \\
\hline Likert: 3 & Likert: 2 & Likert: 0 \\
\hline $\begin{array}{l}\text { Entrevista: } \\
\text { Antes de vendermos nossos } \\
\text { produtos, temos que dar uma aula } \\
\text { sobre eles: se são de uso interno } \\
\text { ou externo, sua densidade, se } \\
\text { pode molhar ou ficar exposto ao } \\
\text { sol, sua flexibilidade, resistência à } \\
\text { compressão, à tração... o que } \\
\text { acontece é que muitos vêm até } \\
\text { nosso estabelecimento apenas } \\
\text { com projetos de arquitetos e } \\
\text { designers [Neste trecho, o } \\
\text { respondente se referia a outras } \\
\text { empresas, não à fábrica } \\
\text { participante do estudo]. Mas } \\
\text { existem muitas madeiras que são } \\
\text { substituíveis; assim podemos } \\
\text { escolher a melhor opção para os } \\
\text { projetos ou móveis. Acho que é } \\
\text { nosso papel participar do processo } \\
\text { decisório da fábrica. Mas acredito } \\
\text { que caso a fábrica possuísse mais } \\
\text { conhecimento e estivesse } \\
\text { atualizada sobre as madeiras e } \\
\text { suas características, poderíamos } \\
\text { obter melhores resultados. }\end{array}$ & $\begin{array}{l}\text { Entrevista: } \\
\text { Quando estamos fazendo os } \\
\text { projetos dos móveis precisamos } \\
\text { contatar os fornecedores, } \\
\text { principalmente quando buscamos } \\
\text { sair da nossa zona de conforto. } \\
\text { Caso nossa empresa conhecesse } \\
\text { melhor o ramo dos fornecedores e } \\
\text { eles o nosso, com certeza } \\
\text { conseguiríamos obter melhores } \\
\text { resultados. A madeireira possui } \\
\text { mais informações técnicas de seus } \\
\text { produtos, mas a compra de um } \\
\text { móvel envolve outros fatores. } \\
\text { Existem móveis que estão em alta, } \\
\text { que são tendência. Isso o } \\
\text { madeireiro não sabe me dizer, mas } \\
\text { a loja de móveis sabe, por isso } \\
\text { precisamos conversar com os dois } \\
\text { lados. O fato de não possuir todas } \\
\text { as informações cria certa } \\
\text { dependência. O ideal seria que } \\
\text { todos conhecessem todas as } \\
\text { etapas e todos os fatores } \\
\text { envolvidos desde criação das } \\
\text { matérias-primas até os fatores } \\
\text { envolvidos na venda de móveis, } \\
\text { mas isso é impossível. } \quad\end{array}$ & $\begin{array}{l}\text { Entrevista: } \\
\text { Nosso negócio não tem } \\
\text { muito segredo. Nós temos } \\
\text { que atender nossos } \\
\text { clientes, entender como } \\
\text { funciona o mercado. Acho } \\
\text { que o nosso aprendizado } \\
\text { e melhoria dependem } \\
\text { muito mais da gente do } \\
\text { que de fornecedores ou } \\
\text { fábricas. }\end{array}$ \\
\hline
\end{tabular}

Figura 8. Respostas obtidas mediante as perguntas referentes ao fator inibidor dependência de aprendizagem mútua

Fonte: Dados da pesquisa.

Autores ressaltam a importância da interdependência entre as empresas e o relacionamento caracterizado pela estabilidade e constância entre as partes (Chen, 2010; Cooper \& Slagmulder, 1999; Herget \& Morris, 1989; O’keeffe, 1998; Souza \& Rocha, 2009). Ressalta-se a importância do conhecimento técnico dos produtos fabricados pelas empresas parceiras e suas atividades. A dependência de aprendizagem mútua se caracterizou pelas partes não conhecerem, em sua totalidade, as atividades e processos envolvidos no negócio das parceiras, como a logística realizada pela madeireira. 
A madeireira explica que percebe a necessidade da fábrica de conhecer melhor os produtos vendidos por ela. Por um lado, isso pode ser percebido como algo positivo, ao passo que aumenta a interdependência entre as empresas. Em contrapartida, a dependência de aprendizagem mútua limita o desenvolvimento de ações coordenadas. Segundo a madeireira e a fábrica, todos os envolvidos no processo produtivo poderiam obter melhores resultados, caso compreendessem melhor as atividades das demais. Do ponto de vista da loja de móveis, a dependência de aprendizagem com a fábrica não é um fator que interfere em seus resultados.

A Figura 9 demonstra as respostas referentes ao fator inibidor sistemas de $\mathrm{GCl}$ muito complexos.

\begin{tabular}{|c|c|c|}
\hline Resposta da Madeireira & Respostas da Fábrica & Respostas da Loja \\
\hline Likert: 0 & Likert: 2 & Likert: 1 \\
\hline $\begin{array}{l}\text { Entrevista: } \\
\text { Agir colaborativamente com as } \\
\text { fábricas e outros compradores } \\
\text { pode ser algo de difícil } \\
\text { execução. Na verdade, a } \\
\text { gente não escolhe quem será } \\
\text { nosso parceiro em longo } \\
\text { prazo; as parcerias e } \\
\text { afinidades entre as empresas } \\
\text { vão acontecendo aos poucos, } \\
\text { e a confiança vai sendo } \\
\text { construída. }\end{array}$ & $\begin{array}{l}\text { Entrevista: } \\
\text { Temos muitos fornecedores e de } \\
\text { muitos produtos e componentes } \\
\text { diferentes. Se dermos atenção a } \\
\text { todos fica impossível administrar } \\
\text { e gerenciar o negócio. Temos que } \\
\text { formar parcerias e conversar } \\
\text { apenas com os fornecedores das } \\
\text { principais matérias-primas, no } \\
\text { nosso caso, são as madeireiras e } \\
\text { os vendedores de estofamentos. } \\
\text { Vejo a construção do } \\
\text { relacionamento como algo } \\
\text { complexo. }\end{array}$ & $\begin{array}{l}\text { Entrevista: } \\
\text { Nós compramos de poucas } \\
\text { marcas de móveis. Não fugimos } \\
\text { de nossas características. Nosso } \\
\text { negócio está pautado em vender } \\
\text { produtos e projetos de alto } \\
\text { padrão. Não considero nossa } \\
\text { empresa como sendo inovadora } \\
\text { ou com um diferencial inigualável } \\
\text { a outras lojas. Tentamos firmar } \\
\text { bons acordos com empresas } \\
\text { locais. Não diria que a parceria } \\
\text { seja algo complexo nem simples. }\end{array}$ \\
\hline
\end{tabular}

Figura 9. Respostas obtidas mediante as perguntas referentes ao fator inibidor sistemas de GCI muito complexos

Fonte: Dados da pesquisa.

A complexidade está relacionada, na visão dos respondentes, ao tempo requerido para a construção dos relacionamentos; assim, os projetos devem ser analisados para cada empresa individualmente, não podendo ser expandidos para qualquer fornecedor ou cliente. Os sistemas de $\mathrm{GCl}$ muito complexos se caracterizam pela variedade de fatores que precisam ser coordenados para que as ações deem 
certo. Os três entrevistados concordaram que, de maneira geral, coordenar esforços com fornecedores/clientes é algo de difícil execução e que existem muitos fatores que não estão sob controle das empresas. A complexidade e a dificuldade em desenvolver e realizar projetos com os clientes e fornecedores foram ressaltadas pelos entrevistados, relacionadas principalmente com a falta de "ideias" e profissionais especializados. Estudos indicam que projetos de gerenciamento de custos interorganizacionais tendem a sucumbir quando são mal elaborados e demasiadamente complexos (Cokins, 1998; Kaplan \& Anderson, 2004; Waeytens \& Bruggeman, 1994).

A Figura 10 demonstra as respostas referentes ao fator inibidor desequilíbrio entre os ganhos de curto e longo prazo.

\begin{tabular}{|c|c|c|}
\hline Resposta da Madeireira & Respostas da Fábrica & Respostas da Loja \\
\hline Likert: 0 & Likert: 1 & Likert: 1 \\
\hline $\begin{array}{l}\text { Entrevista: } \\
\text { Os ganhos acontecem no curto prazo. } \\
\text { Nossas ações ocorrem dentro do } \\
\text { planejamento de um ano. Não } \\
\text { possuímos a capacidade de } \\
\text { planejamento além desse período. } \\
\text { Caso nosso mercado fosse mais } \\
\text { previsível, poderíamos trabalhar com } \\
\text { uma visão em longo prazo. Tenho } \\
\text { muitos clientes que buscam nossos } \\
\text { produtos a pronta entrega e negociam } \\
\text { buscando o menor preço possível, } \\
\text { mas esses são empresas menores... } \\
\text { As grandes fábricas sabem que não } \\
\text { podem trabalhar assim. }\end{array}$ & $\begin{array}{l}\text { Entrevista: } \\
\text { Os benefícios auferidos } \\
\text { ocorrem ao longo do tempo. } \\
\text { O nosso relacionamento, } \\
\text { facilidade de solucionar } \\
\text { problemas e proximidade } \\
\text { são nossas principais } \\
\text { vantagens, mas a } \\
\text { imprevisibilidade não nos } \\
\text { permite criar projetos de } \\
\text { longo prazo. }\end{array}$ & $\begin{array}{l}\text { Entrevista: } \\
\text { Eu percebo que as vantagens } \\
\text { ocorrem numa perspectiva de } \\
\text { curto prazo. Não } \\
\text { desenvolvemos projetos para } \\
\text { os anos futuros, apesar de } \\
\text { possuir a intenção de manter } \\
\text { o relacionamento em longo } \\
\text { prazo. }\end{array}$ \\
\hline
\end{tabular}

Figura 10. Respostas obtidas mediante as perguntas referentes ao fator inibidor desequilíbrio entre os ganhos de curto e longo prazo

Fonte: Dados da pesquisa.

Referindo-se ao desequilíbrio entre ganhos de curto e longo prazo, esse fator pode ser um desencadeador de conflitos entre as empresas. De maneira geral, as empresas tendem a se focar em ganhos de curto prazo (Pereira, Alves, \& Silva, 2010). No caso analisado, afirmaram que focar no curto prazo não é uma escolha, mas uma 
necessidade. Os entrevistados ressaltaram a dinâmica do mercado como uma dificuldade para planejar em longo prazo, sendo a visão em curto prazo algo natural e inevitável ao negócio. Dessa forma, é possível observar que existem fatores inibidores que estão relacionados e são "causados" pelo ambiente no qual as empresas estão inseridas.

Questionados sobre os benefícios gerados pelas relações, como eles acreditam que os benefícios são partilhados entre as partes e se todos se beneficiam das parcerias, os respondentes mostraram consistência em entender que não podem focar em ganhos específicos. Afirmaram que os ganhos ocorrem para a cadeia como um todo, quando os produtos são vendidos ao consumidor final.

Considerando os dados obtidos, a classificação sugerida por Bastl et al. (2010) e a divisão dos fatores inibidores em três grupos, sugeridas por Farias e Gasparetto (2016), foi possível elaborar a Figura 11. Assim, a coluna da esquerda classifica os fatores inibidores segundo os critérios de Bastl et al. (2010), a do meio indica os fatores identificados nos relacionamentos, enquanto a da direita demonstra a qual grupo o fator inibidor foi classificado (Farias \& Gasparetto, 2016). 
Gestão de Custos Interorganizacionais: Fatores inibidores em Empresas do Setor Moveleiro do Distrito Federal Rafael Araújo Sousa Farias, Valdirene Gasparetto

\begin{tabular}{|l|l|l|l|l|}
\hline \multicolumn{1}{|c|}{ Relação } & Ausência de conhecimento especializado \\
programas de educação voltados aos funcionários
\end{tabular}

Figura 11. Fatores inibidores identificados e suas classificações

Fonte: Dados da pesquisa.

Apesar de os relacionamentos entre as empresas existirem há mais de uma década, foi possível identificar fatores inibidores comuns aos três estágios de formação dos relacionamentos interorganizacionais (planejamento das atividades e das estratégias, início das atividades e maturação dos relacionamentos). Isso indica que as empresas não conseguiram superar algumas dificuldades que surgiram ao longo da relação. Indica ainda que, apesar de os fatores trazerem dificuldades aos relacionamentos, não os inviabilizam.

Empregando-se a classificação de Bastl et al. (2010), observa-se que os fatores inibidores predominantes nas empresas pesquisadas estão relacionados, principalmente, a pessoas. Para que esforços interorganizacionais sejam empreendidos com sucesso, o primeiro aspecto a ser trabalhado são as pessoas, que precisam ter conhecimento sobre a importância da visão de processos, do compartilhamento de 
Gestão de Custos Interorganizacionais: Fatores inibidores em Empresas do Setor Moveleiro do Distrito Federal

Rafael Araújo Sousa Farias, Valdirene Gasparetto

informações e da importância de se estabelecer relacionamentos de longo prazo para a melhoria do desempenho de suas cadeias.

A utilização de tecnologias e automação de processos podem tornar as organizações mais eficientes; entretanto, dependem preponderantemente da atuação das pessoas. As empresas podem realizar investimentos específicos em diferentes setores, como investimentos em tecnologia e processos operacionais; entretanto, investimentos em aprendizagem de colaboradores pode melhorar a organização como um todo (Barney \& Hesterly, 1996).

\section{CONSIDERAÇÕES FINAIS}

A presente pesquisa abordou três empresas do setor moveleiro do Distrito Federal e explorou os fatores inibidores da $\mathrm{GCl}$. O estudo identificou oito fatores inibidores presentes nas relações, pertencentes aos três estágios dos relacionamentos interorganizacionais (Farias \& Gasparetto, 2016) e predominantemente relacionados ao fator pessoas (Bastl et al., 2010).

Há de se destacar algumas inferências provenientes da presente pesquisa. Primeiramente, ressalta-se a convergência entre as respostas das empresas analisadas, além da consonância entre suas expectativas. Ainda, observa-se que a falta de treinamento sobre abordagens interorganizacionais não impossibilita sua aplicação; entretanto, tende a dificultar a obtenção de melhores resultados. Além disso, identificase que a percepção, por parte dos gestores, de que as empresas estão "interligadas" é um fator que contribui para a coordenação de esforços com clientes e fornecedores. Ademais, percebe-se que, quando as empresas não conhecem os processos e atividades das demais, a realização de atividades conjuntas fica prejudicada.

Ainda em direção às inferências, conclui-se que $O$ ambiente e questões relacionadas à economia e legislação interferem nos fatores inibidores da $\mathrm{GCl}$. A alteração no poder de compra das famílias, mudanças na legislação, impostos e 
questões ambientais dificultam o gerenciamento das ações em longo prazo. Ainda, compreende-se que existem fatores condicionantes da $\mathrm{GCl}$ que, para serem atingidos, precisam superar mais de um fator inibidor. Por exemplo, para que as empresas consigam compartilhar informações, devem reconhecer a importância dos sistemas de custeio, conseguir gerar informações confiáveis e aceitar compartilhar informações. Ademais, ressalta-se a dificuldade das empresas consideradas "não importantes" em constituir relacionamentos em longo prazo, devido à facilidade de serem substituídas.

Finalizando as inferências possíveis a partir da presente pesquisa, destaca-se a existência de diferentes interesses das empresas, dependendo do seu posicionamento na cadeia produtiva. Por exemplo, a empresa que está na ponta da cadeia (loja) relata as percepções dos clientes para os demais membros; além disso, não possui relevante interesse nos processos produtivos e custos quanto à madeireira. Por sua vez, a madeireira e a fábrica procuram compartilhar mais informações relacionadas às matérias-primas brutas e seus custos. Por fim, atenta-se que bons relacionamentos com clientes e fornecedores facilitam a comunicação entre as empresas e possibilitam a rápida resolução de problemas. Além disso, as negociações se tornam mais fáceis.

Como apontado, são muitos os fatores que interferem na aplicabilidade da $\mathrm{GCl}$. Assegura-se que a presente pesquisa não pretende esgotar o assunto, uma vez que os fatores inibidores variam conforme a ambiência em que as empresas estão inseridas. Acredita-se que diagnosticar os fatores que inibem o sucesso da abordagem da $\mathrm{GCl}$ apresenta contribuições teóricas e práticas, respeitando-se naturalmente, as limitações do estudo.

Quanto às contribuições teóricas, o estudo vai de encontro à literatura que aponta que o inter-relacionamento é algo benéfico às empresas, sem ressaltar as dificuldades envolvidas no processo. Essa situação pode levar à percepção de que agir colaborativamente com outras empresas pode ser a solução de todos os problemas organizacionais e que, necessariamente, vai trazer vantagens econômicas para as organizações. 
Gestão de Custos Interorganizacionais: Fatores inibidores em Empresas do Setor Moveleiro do Distrito Federal

Rafael Araújo Sousa Farias, Valdirene Gasparetto

A literatura acerca da $\mathrm{GCl}$ ressalta a importância da relação de poder entre as empresas, sendo considerada mais indicada para os relacionamentos que envolvem uma empresa que "monopoliza" o mercado - para que as demais tenham mais interesse em coordenar esforços. Conclui-se que a relação de poder não é determinante para que as empresas se aproximem. No caso analisado, as empresas não consideram uma mais importante do que a outra. $O$ fator que mais motivou as empresas a valorizarem os relacionamentos foi a interdependência para atingir objetivos e não relações de poder.

Observa-se que determinadas particularidades aproximaram as empresas, como a interdependência para atingir objetivos em comum, a baixa quantidade de fornecedores para determinados componentes - madeiras nobres - e estabilidade nos relacionamentos. Essas particularidades são apontadas pela teoria e puderam ser confirmadas na prática. Outra identificação da pesquisa que corrobora a literatura é o fato de que, quando as empresas não conhecem os processos e atividades das demais, a realização de atividades conjuntas fica prejudicada.

Outro ponto relacionado à teoria é o fato de que parece haver correlação e interferência entre os fatores inibidores. Por exemplo, quanto à ausência de conhecimento especializado e programas de educação voltados aos funcionários, segundo os respondentes, esse fator acentua outras dificuldades enfrentadas pelas empresas, como no desenvolvimento de novas ideias, a complexidade do relacionamento e as dificuldades em executar os projetos da $\mathrm{GCl}$. Mais estudos são necessários para fazer afirmações acerca das correlações e interferências dos fatores inibidores, mas a presente pesquisa levantou o tema.

Quanto às contribuições práticas, a análise conjunta dos fatores inibidores com a realidade das empresas contribui com a redução dos riscos relacionados à implementação da abordagem. O estudo contribui com a amenização da visão de que não há riscos e problemas no relacionamento entre as empresas. Ademais, de fato a GCI se mostrou um fenômeno interdisciplinar e que os relacionamentos colaborativos 
entre fornecedores e clientes são pautados em muitos fatores distintos. Contudo, esse cenário mostrou que as empresas podem, mesmo sem possuírem gestores com vasto conhecimento na área, aplicar a $\mathrm{GCl}$. Naturalmente, os resultados esperados são menores, contudo, não inviabilizados.

Outra contribuição prática relaciona-se com a identificação do fato de que a implementação da $\mathrm{GCl}$ pode encontrar dificuldade caso a empresa não possua capacidades internas, como a compreensão e capacidade de apurar custos. Constatase que, primeiramente, as empresas devem superar as barreiras internas e suas deficiências para, então, dispensar esforços interorganizacionais. Ademais, outra questão que os gestores devem considerar é se as empresas de sua cadeia percebem e consideram que estão interligadas, pois isso mostrou ser um fator que facilita a colaboração entre os gestores.

Sugere-se que trabalhos futuros deem continuidade aos estudos dos fatores inibidores da $\mathrm{GCl}$, analisando as relações existentes entre eles. Pesquisas que analisem se o foco estratégico e as idiossincrasias das empresas influenciam na aplicabilidade da $\mathrm{GCl}$ é outra oportunidade de pesquisa. Recomenda-se conduzir pesquisas com enfoque interdisciplinar que busquem estudar mecanismos destinados a amenizar e dirimir as dificuldades trazidas pelos fatores inibidores. Por fim, sugere-se que pesquisas avaliem se os fatores inibidores da $\mathrm{GCl}$ variam conforme a localização em que as empresas estão inseridas dentro de uma cadeia produtiva. De fato, o estudo relacionado à Gestão de Custos Interorganizacionais e os desafios encontrados em sua abordagem apresentam oportunidades para pesquisas futuras que visem desenvolver 0 conhecimento acerca da tarefa de gerenciar custos de maneira interorganizacional.

\section{REFERÊNCIAS}

Abimóvel. (2016). Associação Brasileira das Indústrias do Moveleiro. Recuperado de: $<$ http://www.abimovel.com/>. Acesso em: jan./2016. 
Gestão de Custos Interorganizacionais: Fatores inibidores em Empresas do Setor Moveleiro do

Distrito Federal

Rafael Araújo Sousa Farias, Valdirene Gasparetto

Aguiar, A. B., Rezende, A. J., \& Rocha, W. (2008). Uma análise da complementaridade entre Gestão Interorganizacional de Custos e Open-Book Accounting. BASE Revista de Administração e Contabilidade da Unisinos, 5(1), 66-76.

Alves, R. R., Cabral, C. P. T., Souza, M. O. A., Vidaurre, G. B., Colli, A., \& Silva, J. C. (2008). Diagnóstico e caracterização das marcenarias na cidade de Viçosa-MG. Semina: Ciências Agrárias, 29(4), 789-798.

Amato Neto, J. (2000). Redes de cooperação produtiva e clusters regionais: oportunidades para as pequenas e médias empresas (1a ed.). São Paulo: Atlas.

Atouba, Y., \& Shumate, M. (2010). Interorganizational networking patterns among development organizations. Journal of Communication, 60(2), 293-317.

Balestrin, A., Verschoore, J. R., \& Reyes Jr., E. (2010). O campo de estudo sobre redes de cooperação interorganizacional no Brasil. Revista de Administração Contemporânea, 14(3), 458-477.

Barney, J., \& Hesterly, W. (1996). Organizational economics: understanding the relationship between organizations and economic analysis (1a ed.). London: Sage.

Bastl, M., Grubic, T., Templar, S., Harrison, A., \& Fan, I.-S. (2010). Inter-organizational costing approaches: the inhibiting factors. The International Journal of Logistics Management, 21(1), 65-88.

Boddy, D., Macbeth, D., \& Wagner, B. (2000). Implementing collaboration between organizations: an empirical study of supply chain partnering. Journal of Management Studies, 37(7), 1003-1017.

Camacho, R. R., Rocha, W., Moraes, R. O., \& Marques, K. C. M. (2015). Gestão de Custos Interorganizacionais: evidências empíricas em hospitais privados no Brasil. Revista de Administração Hospitalar e Inovação em Saúde, 12(2), 19-33.

Camacho, R. R., Rocha, W., Moraes, R. O., \& Marques, K. C. M. (2014). Evidências de práticas da Gestão de Custos Interorganizacionais na Cadeia de Valor de hospitais privados no Brasil. Revista de Contabilidade e Controladoria, 6(2), 90-105.

Campos, L. C., Oliveira, K. G., Leal, E. A., \& Duarte, S. L. (2015). Gestão de Custos Interorganizacionais: um estudo da "rede cerrado" de supermercados. Revista Contabilidade Vista e Revista, 27(3), 81-104.

Carter, C., Rogers, D., \& Choi, T. (2015). Toward the theory of the supply chain. Journal of Supply Chain Management, 51(2), 1-25. 
Chen, B. (2010). Antecedents or processes? Determinants of perceived effectiveness of interorganizational collaborations for public service delivery. International Public Management Journal, 13(4), 381-407.

Coad, A., \& Scapens, R. (2006). Inter-organisational cost management. Financial Management, 35(2), 38-39.

Cokins, G. (1998). Why is traditional accounting failing managers? Hospital Material Management Quarterly, 20(2), 72-80.

Cokins, G. (2003). Measuring profits and costs across the supply chain for collaboration. Cost Management, 17(5), 22-29.

Cooper, R., \& Slagmulder, R. (1999). Supply chain development for the lean enterprise: interorganizational cost management (1a ed.). New Jersey: The IMA Foundation for Applied Research.

Cooper, R., \& Slagmulder, R. (2003). Interorganizational costing - Part 1. Cost Management, 17(5), 14-21.

Davenport, T., Harris, J., \& Cantrell, S. (2004). Enterprise systems and ongoing process change. Business Process Management Journal, 10(1), 16-26.

Dekker, H. (2004). Control of inter-organizational relationships: evidence on appropriation concerns and coordination requirements. Accounting, Organizations and Society, 29(1), 27-49.

Doz, Y. (1996). The evolution of cooperation in strategic alliances: initial conditions or learning processes? Strategic Management Journal, 17(1), 55-83.

Dyer, J., \& Hatch, N. (2006). Relation-specific capabilities and barriers to knowledge transfers: creating advantage through network relationships. Strategic Management Journal, 27(8), 701-719.

Ellram, L. (1996). A structured method for applying purchasing cost management tools. International Journal of Purchasing and Materials Management, 32(1), 20-28.

Faria, A. C., Soares, I. C., Rocha, W., \& Rossi, G. B. (2013). A prática da Gestão de Custos Interorganizacionais em uma montadora de veículos na região do Grande ABC. Revista Brasileira de Gestão de Negócios, 15(49), 617-638.

Farias, R. A. S. (2016). Gestão de Custos Interorganizacionais: estudo sobre os fatores inibidores em empresas do setor moveleiro do Distrito Federal (Dissertação de 
Gestão de Custos Interorganizacionais: Fatores inibidores em Empresas do Setor Moveleiro do

Distrito Federal

Rafael Araújo Sousa Farias, Valdirene Gasparetto

Mestrado). Universidade Federal de Santa Catarina - UFSC, Florianópolis, SC, Brasil.

Farias, R. A. S., \& Gasparetto, V. (2015). Gestão de Custos Interorganizacionais: um estudo bibliométrico. Sociedade, Contabilidade e Gestão, Rio de Janeiro, 10(3), 80104.

Farias, R. A. S., \& Gasparetto, V. (2016). Inhibiting Factors of Interorganizational Cost Management: Complementary Study. International Business Research, 9(8), 91-105.

Farias, R. A. S., Gasparetto, V., Lunkes, R. J., \& Schnorrenberger, D. (2016). Gestão de Custos Interorganizacionais: análise da aplicabilidade em uma rede de supermercados de grande porte. ConTexto, 16(32), 4-19.

Fehr, L. C. F. A., \& Duarte, S. L. (2018). Gestão de Custos Interorganizacionais e OpenBook Accounting: as duas faces da mesma moeda. Revista de Contabilidade do Mestrado em Ciências Contábeis da UERJ, 23(1), 70-87.

Flesch, V. (2010). Controladoria como suporte de gestão das indústrias moveleiras na Região Oeste de Santa Catarina. Revista Catarinense da Ciência Contábil, 9(27), 7992.

Gonzaga, R. P., Aillón, H. S., Fehr, L. C. F. A., Borinelli, M. L., \& Rocha, W. (2015). Mecanismos disciplinadores da Gestão de Custos Interorganizacionais e Economia dos Custos de Transação: um ensaio teórico. Revista de Educação e Pesquisa em Contabilidade, 9(3), 258-274.

Grandori, A., \& Soda, G. (1995). Interfirms network: antecedents, mechanisms and forms. Organization Studies, 16(2), 183-214.

Hair Jr., J., Barry, B., Money, A., \& Samouel, P. (2005). Fundamentos de métodos de pesquisa em administração (1a ed.). Porto Alegre: Bookman.

Herget, M., \& Morris, D. (1989). Accounting data for value chain analysis. Strategic Management Journal, 10(2), 175-188.

Himme, A. (2012). Critical success factors of strategic cost reduction - results from an empirical survey of German cost reduction projects. Journal of Management Control, 23(3), 183-210.

Horn, B., Bonfatti, T. R., \& Raupp, F. M. (2018). Avaliação da Gestão de Custos Interorganizacionais em função de seus fatores condicionantes: um estudo em uma empresa de serviços arquitetônicos. Meta: Avaliação, 10(29), 473-501. 
Gestão de Custos Interorganizacionais: Fatores inibidores em Empresas do Setor Moveleiro do

Distrito Federal

Rafael Araújo Sousa Farias, Valdirene Gasparetto

IPT - INSTITUTO DE PESQUISAS TECNOLÓGICAS. (2002). Prospectiva tecnológica da cadeia produtiva madeira e móveis (1a ed.). São Paulo: IPT.

Kajüter, P., \& Kulmala, H. (2005). Open Book Accounting in networks: potential achievements and reasons for failures. Management Accounting Research, 16(2), 179-204.

Kaplan, R., \& Anderson, S. (2004). Time-Driven Activity-Based Costing. Harvard Business Review, 82(11), 131-138.

Kulmala, H., Paranko, J., \& Uusi-Rauva, E. (2002). The role of cost management in network relationships. International Journal of Production Economics, 79(1), 33-43.

Kumra, R., Agndal, H., \& Nilsson, U. (2012). Open book practices in buyer-supplier relationships in India. Journal of Business \& Industrial Marketing, 27(3), 196-210.

Kunzler, M., \& Bulgacov, S. (2011). As estratégias competitivas e colaborativas e os resultados individuais e coletivos no associativismo rural em Quatro Pontes-PR. Revista de Administração Pública, 45(5), 1363-1393.

Lai, F., Zhang, M., Lee, D., \& Zhao, X. (2012). The impact of supply chain integration on mass customization capability: an extended resource-based view. Engineering Management, 59(3), 443-456.

Lalonde, B., \& Pohlen, T. (1996). Issues in supply chain costing. The International Journal of Logistics Management, 7(1), 1-11.

Lambert, D., \& Cooper, M. (2000). Issues in supply chain management. Industrial Marketing Management, 29(2), 65-83.

Lee, S., \& Monge, P. (2011). The coevolution of multiplex communication networks in organizational communities. Journal of Communication, 61(4), 758-779.

Martins, G. A., \& Theóphilo, C. R. (2009). Metodologia da investigação científica para ciências sociais aplicadas (2a ed.). São Paulo: Atlas.

Miles, R., \& Snow, C. (1992). Causes of failure in network organizations. California Management Review, 34(4), 53-72.

Moura, M. F., \& Lima, N. C. (2016). Gestão de Custos Interorganizacionais para o gerenciamento dos Custos Totais: estudo de caso em uma usina de cana-de-açúcar na região do triângulo mineiro. Revista Evidenciação Contábil \& Finanças, 4(1), 6583. 
Gestão de Custos Interorganizacionais: Fatores inibidores em Empresas do Setor Moveleiro do

Distrito Federal

Rafael Araújo Sousa Farias, Valdirene Gasparetto

Müller-Seitz, G. (2011). Leadership in interorganizational networks: a literature review and suggestions for future research. International Journal of Management Reviews, 14(4), 428-433.

Nascimento, S., Pereira, A. M., \& Scarpin, J. E. (2012). Os fatores condicionantes da Gestão de Custos Interorganizacionais em uma indústria metalúrgica da cidade de Rio do Sul - SC. ABCustos: Associação Brasileira de Custos, 7(2), 01-25.

Nassimbeni, G. (1998). Network structures and coordination mechanisms: a taxonomy. International Journal of Operations \& Production Management, 18(6), 538-554.

O'keeffe, M. (1998). Establishing supply chain partnerships: lessons from Australian agribusiness. Supply Chain Management, 3(1), 5-9.

Oliveira, W. S., Borges, W. G., Carvalho, L. F., \& Santos, G. C. (2016). Gestão de Custos Interorganizacionais: uma pesquisa bibliométrica com base em publicações nacionais. RAGC, 4(6), 62-74.

Oliver, C. (1990). Determinants of interorganizational relationships: integration and future directions. Academy of Management Review, 15(2), 241-265.

Pereira, B. A. D., Alves, J. N., \& Silva, P. E. (2010). O lado obscuro dos relacionamentos interorganizacionais: por que as empresas saem dos processos cooperativos? Espacios, 31(4), 25-27.

Poletto, C., Duarte, M., \& Mata, W. (2011). Gestão compartilhada de P\&D: o caso da Petrobras e a UFRN. Revista de Administração Pública, 45(4), 1095-1117.

Porter, M. (1989). Vantagem competitiva: criando e sustentando um desempenho superior (12a ed.). Rio de Janeiro: Elsevier.

Ramos, M. M. (2004). Interaction between management accounting and supply chain management. Supply Chain Management: An International Journal, 9(2), 134-138.

Ring, P. S., \& Van De Ven, A. H. (1994). Developmental processes of cooperative interorganizational relationships. The Academy of Management Review, 19(1), 90-118.

Souza, B. C., \& Rocha, W. (2009). Gestão de custos interorganizacionais: ações coordenadas entre clientes e fornecedores para otimizar resultados (1a ed.). São Paulo: Atlas.

Souza, M. A., Braga, A. V., \& Krombauer, C. A. (2014). Mapeamento da Gestão de Custos Interorganizacionais: uma meta-análise envolvendo pesquisadores, métodos e discussões. ConTexto, 14(28), 41-52. 
Stephenson, G. (2003). The somewhat flawed theoretical foundation of the extension service. Journal of Extension, 41(4), 16-30.

Subramanian, R., \& Ishak, S. (1998). Competitor analysis practices of US companies: an empirical investigation. Management International Review, 38(1), 7-23.

Turrini A., Cristofoli, D., Frosini, F., \& Nasi, G. (2010). Networking literature about determinants of network effectiveness. Public Administration, 88(2), 528-550.

Waeytens, D., \& Bruggeman, W. (1994). Barriers to successful implementation of ABC for continuous improvement: a case study. International Journal of Production Economics, 36(2), 39-52.

Xavier Júnior, H. P., \& Lima, N. C. (2018). A evidenciação de Custos Interorganizacionais em uma empresa do agronegócio brasileiro. ABCustos: Associação Brasileira de Custos, 13(2), 107-133.

Yamanoi, J., \& Cao, Q. (2014). Competition and termination of the alliances between asymmetric partners: the case of Japanese department stores. Asia Pacific Journal of Management, 31(4), 949-971.

Yan, A., \& Gray, B. (1994). Bargaining power, management control, and performance in United States-China joint ventures: a comparative case study. Academy of Management Journal, 37(6), 1478-1517.

Data de Submissão: 28/02/2019

Data de Aceite: 10/07/2019 